\title{
Antimicrobial effect of Pistacia atlantica leaf extract
}

\author{
Mohamad Ali Roozegar1, Farid Azizi Jalilian², Mohamad Reza Havasian³ ${ }^{3}$ Jafar Panahi $^{3}$ \& Iraj \\ Pakzad ${ }^{4,5, *}$
}

${ }^{1}$ Department of Periodentistry, Faculty of Dentistry, Ilam University of Medical Sciences, Ilam/Iran; ${ }^{2}$ Department Microbiology, Faculty of Medicine, Hamadan University of Medical Sciences, Hamadan/ Iran; ${ }^{3}$ Mostafa Khomeini Hospital, Ilam University of Medical Sciences, Ilam/Iran; ${ }^{4}$ Department Microbiology, Faculty of Medicine, Ilam University of Medical Sciences, Ilam/Iran; ${ }^{5}$ Clinical Microbiology Research Center, Ilam University of Medical Sciences, Ilam/Iran; Iraj Pakzad - Email: mpvmpv559@gmail.com; *Corresponding author

Received January 05, 2016; Accepted January 07, 2016; Published January 31, 2016

\begin{abstract}
:
The antimicrobial effect of the mastic tree (Pistacia atlantica) under in vitro conditions has been reported. Therefore, it is of interest to evaluate the effect of the plant leaf extract (aqueous) on bacterial load in mouth and saliva. The leaf of the Pistacia atlantica plant was collected and cleaned, dried at $40^{\circ} \mathrm{c}$ and then powdered. The extraction was carried out using the maceration method in vacuum with the rotary evaporator device. Bacterial inhibition (Streptococcus species) by the leaf extract was studied using the disc diffusion and embedding sink diffusion methods. The values of MIC and MBC were determined. The collected data was further analyzed using t-test and repeated measure statistical tests. The disc diffusion technique showed a significant inhibitory effect for Pistacia atlantica's leaf extract on S. mutans (ATCC 35668) and S. mitis (ATCC 49456) with inhibition zones of 19 and 25 millimeters, respectively. This is for the highest leaf extract concentration used in this study $(\mathrm{p}<0.01)$. The values of MIC and MBC for $S$. mutans was $60,90 \mu \mathrm{g} / \mathrm{ml}$ and for $S$. mitis was $75,110 \mu \mathrm{g} / \mathrm{ml}(\mathrm{p}<0.01$ significance). The leaf extract has no significant effect on $S$. salivarius (ATCC 13419). Thus, the antimicrobial properties of the aqueous leaf extract from Pistacia atlantica is demonstrated in this study.
\end{abstract}

Keywords: Pistacia atlantica, leaf extract, anti-bacterial, Streptococcus mutans, Streptococcus mitis, Streptococcus salivarius

Streptococcus mutans is gram-positive cocci and is a facultative anaerobe that exists in the normal flora of the human mouth. It is the most important factor in dental caries [1, 2]. S. salivarius is a type of streptococcus which exists in the normal flora of the mouth and in the upper respiratory system of humans. This bacterium is known as an opportunistic pathogen. It often causes septicemia in patients with neutropenia in the blood circulatory system $[3,4]$.

S. mitis is an alpha hemolytic and mesophilic type of Streptococcus (genus), which inhabits the oral cavity. These bacteria can cause endocarditis [5, 6]. The treatment of the disease using extracts from several plant parts is known through regional yet traditional practice and possible documentation in several parts of the world. The modern drug discovery process using advanced robotic screening of traditionally known plant parts is well known [7]. The use of plant derived herbal products as food supplements for ISSN 0973-2063 (online) 0973-8894 (print) BIOINFORMATION 12(1): 19-21 (2016) medication is largely in practice [8-9]. The Pistacia (genus) plant is known for its medicinal property. The plant species $P$. atlantica mutica (sub species) and $P$. atlantica kurdica (sub species) is in the northern mountains of the Iranian Ilam province.

The antimicrobial properties of the native species are known [10-12]. The use of different species of Pistachio as antibacterial, antifungal, antiviral, anti-atherogenic, hypoglycemia, antitumor and facilitating hepatic function is known [9]. Therefore, it is of interest to evaluate the effect of $P$. atlantica leaf extract (aqueous) on bacterial (S. mutans, S. mitis and S. salivarius.) load in mouth and saliva.

\section{Methodology:}

Collection and extraction of the P. atlantica leaf

The plant leaf was collected from the mountains of the Ilam province. The leaf is rinsed with water, dried at $40^{\circ} \mathrm{C}$ and then 
powdered [13]. Subsequently, 10 grams of powdered plant leaf was mixed with $200 \mathrm{ml}$ of boiled distilled water and the solution was mixed constantly for 20 minutes. It was then poured into a close lid container and kept at room temperature. The solution was passed through a fabric filter with fine texture. The filtered extracted solution was centrifuged for 15 minutes at $3500 \mathrm{rpm}$ and then it was exposed to air until the solvent had completely evaporated to retain the powder [14].

\section{Bacteria}

Bacterial standard strains of Streptococcus mutans (ATCC 35668), Streptococcus mitis (ATCC 49456) and Streptococcus salivarius (ATCC 13419) were used. The BHI broth and agar and chocolate agar culturing medium was used in an environment with $5 \% \mathrm{CO}_{2}$ for initial culturing. The sensitivity test of the bacteria was analyzed in the Mueller Hinton agar medium (Pronadisk co. Italy) containing 5\% de-fibrinated blood was used.

\section{Disk diffusion Method}

This method was completed using a $1 \times 10^{8} \mathrm{CFU} / \mathrm{ml}$ suspension of bacteria and blank disks with a diameter of $6.4 \mathrm{~mm}$ (MAST Co. UK) treated with different concentrations of the extract $(5$, $10,20,40,80$ and $100 \mathrm{mg} / \mathrm{ml}$ ) were used. Mueller Hinton agar culture medium containing 5\% de-fibrinated blood under completely sterile conditions was used as described elsewhere $[15,16]$. The results were checked at 24,48 and 72 hours after culturing. Amoxicillin with a concentration of $25 \mu \mathrm{g} / \mathrm{ml}$ (MAST Co. UK) was used as positive control and blank disks were used as negative control in this experiment.

\section{Embedding sink diffusion method}

The diffusion in agar method was used with slight modifications. Wells with a diameter of $5 \mathrm{~mm}$ were created in the Mueller Hinton agar medium after adding $1 \times 10^{8} \mathrm{CFU} / \mathrm{ml}$ of the species to the intended medium. The bottom of each well was obstructed with Mueller Hinton agar under sterile conditions in order to prevent the extract from diffusing under the medium. 25 microns of the different concentrations $(5,10$, $20,40,80$ and $100 \mathrm{mg} / \mathrm{ml}$ ) was added in each well and after 2448 hours the results were recorded $[\mathbf{1 7}, \mathbf{1 8}]$.

\section{MIC determination}

The micro-broth dilution method was used to determine MIC. Solutions with concentrations $(100,200$ and $400 \mu \mathrm{g} / \mathrm{ml})$ were added in $2 \mathrm{ml}$ Mueller Hinton Broth medium. $20 \mu \mathrm{l}$ of bacteria suspension with turbidity equal to $0.5 \mathrm{McF}$ arland was added to each tube. Then the tubes were incubated at $35^{\circ} \mathrm{C}$ for 24 hours [19].

\section{MBC determination}

The MBC determination method is similar to the method used for MIC with the difference that bacteria counting were carried out on test tubes with concentrations of MIC and or higher [19].

\section{Statistical analysis}

The results were analyzed using the SPSS (version 18) software. The t-test and repeated measure statistical tests were used for the analysis [14].
Table 1: Streptococcus inhibition by $P$. atlantica leaf extract using disk and embedding sink diffusion methods.

\begin{tabular}{lccc}
\hline Species & $\begin{array}{c}\text { Extract } \\
\text { Concentration } \\
(\mathrm{mg} / \mathrm{ml})\end{array}$ & \multicolumn{2}{c}{ Inhibition zone $(\mathrm{mm})$} \\
\cline { 3 - 4 } & 5 & 5 & Diffusion methods \\
\hline S. mutans & 10 & 8.5 & Embedding sink \\
& 20 & 11 & 5 \\
& 40 & 20 & 8 \\
& 80 & 25 & 15 \\
S. mitis & 100 & 25 & 21 \\
& 5 & 0 & 22 \\
& 10 & 3.5 & 0 \\
& 20 & 7 & 0 \\
& 40 & 15.5 & 5 \\
S. salivarius & 80 & 18 & 5 \\
& 100 & 19 & 9 \\
& 5 & 0 & 13 \\
& 10 & 0 & 0 \\
& 20 & 4 & 0 \\
& 40 & 5 & 4 \\
& 80 & 5 & 6 \\
& 100 & 5 & 6 \\
\hline
\end{tabular}

\section{Results:}

Disk diffusion and creating wells

The results from disk diffusion and creating wells showed a significant inhibitory effect of the aqueous leaf extract on the standard strains of $S$. mutans with a halo of 25 and $22 \mathrm{~mm}$ for the highest concentration of the extract Table 1 ( $\mathrm{P}<0.01)$. The results also showed the suitable effect of the extract on the standard strain of $S$. mitis under in vitro conditions Table 1 $(\mathrm{P}<0.01)$. However, the data showed a weak effect on $S$. salivarius for the highest extract concentration (Table 1) $(\mathrm{P}<0.01)$.

\section{MIC and MBC results}

The results from the micro dilution method showed that the MIC of the extract for S. mutans and S. mitis is 60 and $75 \mu \mathrm{g} / \mathrm{ml}$, respectively. The MBC of the extract on $S$. mutans and $S$. mitis is 90 and $115 \mu \mathrm{g} / \mathrm{ml}$, respectively $(\mathrm{P}<0.01)$.

\section{Discussion:}

The use of medicinal plants derived compounds for treatment of illness is traditional and often believed to be simple yet naturally safe [20]. The application of herbal medicine as antimicrobial agent is an alternative solution where anti-biotic resistance is ascertained [21-24]. The undesired effects of several synthetic compounds as drugs are known [25]. Therefore, it is of interest to evaluate the effect of $P$. atlantica leaf extract (aqueous) on bacterial (S. mutans, S. mitis and $S$. salivarius) load in mouth and saliva. The Pistacia plant is known for its medicinal properties and its antibacterial effects are known [26, 27]. The two sub-species of $P$. atlantica mutica and $P$. atlantica kurdica are available in plenty in the northern mountains of Ilam province in Iran. Their use for medicinal purpose is of relevance.

We studied the anti-bacterial effect of its leaf extract (aqueous) on selected Streptococcus species (S. mutans, S. mitis and S. salivarius). Results showed the strong effect of the $P$. atlantica plant leaf extract on S. mutans with a MIC of 60 and MBC of 90 
$\mu \mathrm{g} / \mathrm{ml}$. The aqueous extract of this plant also had desirable effects on S. mitis with a MIC of 90 and MBC of $115 \mu \mathrm{g} / \mathrm{ml}$. However, the leaf extract has no significant effect on $S$. salivarius (ATCC 13419). Azimi Laysar et al. (2013) showed the effect of different concentrations of Nigella on the growth of Streptococcus mutans [28]. The results showed that the effects were not as strong as the leaf extract of $P$. atlantica. Azizianet et al (2013) showed the antimicrobial effect of the plant $P$. atlantica aqueous extract on Streptococcus mutans [29]. Results showed that the inhibitory effect of the extract was stronger than amoxicillin disks but this difference is not statistically significant $(\mathrm{P}>0.01)$. Thus, results show that the antimicrobial effects of the aqueous extract from the leaf of the Pistacia atlantica plant are stronger and more desirable compared to other plant extracts $[30,31,32,33]$.

\section{Conclusion:}

Data presented in this report show the effect of the plant Pistacia atlantica leaf extract on S. mutans and its desirable effects on S. mitis. The leaf extract is rich in phenol compounds and it is implied to be associated with anti-bacterial properties [34]. Further studies are necessary to determine the anti-cellular effects of the plant extract.

\section{Acknowledgment:}

We wish to express our appreciation for the support provided by the Research Center for Periodontics, Medical University of Ilam, Iran.

\section{References:}

[1] Khoramian Tusi S et al. J Mash Dent Sch. 2014 38: 321

[2] Beheshti-Rouy M et al. Iran J Microbiol. 2015 7: 173 [PMID: 26668706]

[3] Afek S et al. J Clin Gastroenterol. 2004 38: 86 [PMID: 14679337]

[4] Legier JF, South Med J. 1991 84: 1058 [PMID: 1882265]

[5] Chen JH et al. J Clin Pathol. 2015 68: 652 [PMID: 25972224]

[6] Contargyris Cet al. Ann Fr Anesth Reanim. 2012 31: 827 [PMID: 23021619]

[7] Eisenberg DM et al. JAMA. 1998 280: 1569 [PMID: 9820257]

[8] Bosze S. Tropical ecosystem of Costa Rica. 2000.

[9] Peksel A et al. J food biochemistry. 2010 34: 451

[10] Hatamnia AA et al. Nat Prod Res. 2015 8: 1 [PMID: 25853287]

[11] Sharifi MS et al. Glob J Health Sci. 2011 4: 149 [PMID: 22980106]

[12] Taran M et al. Iran J Public Health. 2010 39: 36 [PMID: 23112988]

[13] Kusterer J \& Keusgen M, J Agric Food Chem. 2010 58: 1129 [PMID: 20030404]

[14] Judaki A et al. Bioinformation. 2014 10: 689 [PMID: 25512685]

[15] Salman MT et al. J Unimed Kulliyat. 2006 2: 8.

[16] Betty A et al. Bailey \& Scott's Diagnostic Microbiology. 1998 256.

[17] Jainkittivong A et al. Oral Surg Oral Med Oral Pathol Oral Radiol Endod. 2009 108: 394 [PMID: 19716507]

[18] Nascimento GFL et al. Braz J Microbiol. 2000 31: 347

[19] Niakan M et al. J Res Dent Sci. 2011 8: 75

[20] Kaefer CM et al. J Nutr Biochem. 2008 19: 347

[21] Cowan MM. Clin Microbiol Rev. 1999 12: 564 [PMID: 10515903]

[22] Ayfetr D et al. Turk J Boil. 2003 27: 157

[23] Mitra Azizian et al. Biomedical \& Pharmacology Journal. 2013 6: 133

[24] Mohamadi J et al. Bioinformation 2014 10: 667 [PMID: 25512681]

[25] Egorov NS. MIR Publishers. Moscow. 1985

[26] Rahimzadeh GH et al. Microbiology of food. 2014 1: 49

[27] Hosseini M et al. J of Ofoghe Danesh. 2015 4:19

[28] Azimi Laysar H et al. J Res Dent Sci. 2013 9: 179

[29] Shoa Hasani A. Rahavard Danesh. 2009 11: 87

[30] Panahi J et al. Scientific J Ilam University of Medical Sciences. 2013 21: 54

[31] Roozegar MA et al. J Evolution Med and Dent Sci. 2014 3: 86

[32] Panahi J et al. J Pharm Biomed Sci. 2013 3: 5

[33] Roozegar MA et al. International Research Journal of Biological Sciences. 2014 3: 63

[34] Farzanegi P et al. Zahedan J Research in Medical Sciences. 2013 15: 59

Edited by P. Kangueane

Citation: Roozegar et al. Bioinformation 12(1): 19-21 (2016)

License statement: This is an Open Access article which permits unrestricted use, distribution, and reproduction in any medium, provided the original work is properly credited. This is distributed under the terms of the Creative Commons Attribution License.

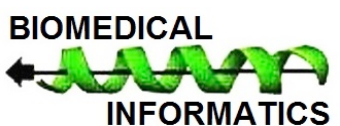

